\title{
Ağrının kronikleşmesine neden olan faktörler, patofizyoloji temelli tedaviler
}

\author{
Factors related with chronicity of pain, pathophysiology-based therapies
}

\author{
Işın Ünal-Çevik \\ Hacettepe Üniversitesi Tıp Fakültesi, Nöroloji Anabilim Dalı, Ağrı Ünitesi, Ankara
}

\begin{abstract}
Akut ağrı, erken tanı konulup, risk faktörleri belirlenip, etkin tedavi edilmezse, kronik ağrıya dönüşebilir. Pek çok kas-iskelet sistemi ağrılarında periferik nosiseptif uyarı gereklidir. Ancak, bunun varlığı kronik ağrılı hastalarda gözlenen ağrı süresi ya da şiddeti ile doğru orantılı değildir. Çevresel, genetik, psikososyal ve nörofizyolojik faktörler kronik ağrı semptomatolojisinde önemli belirleyiciler arasındadır. Ağrının kronikleşmesine neden olan risk faktörleri ve tanı mekanizmalarının bilinmesi, hem önleyici yaklaşımların oluşturulmasında hem de etkin tedavi yöntemlerinin geliştirilmesinde bize yol gösterecektir.
\end{abstract}

Anahtar sözcükler: sensitizasyon; fasilitasyon; disinhibisyon; reorganizasyon; komorbidite
When acute pain is not diagnosed early, the risk factors assessed promptly and treated effectively, it may progress into chronic pain. In many chronic musculoskeletal pain conditions, peripheral nociceptive input is necessary but not sufficient to explain the presence, duration and intensity of patients' pain. Environmental, genetic, psychosocial and neurophysiological factors are important determinants in chronic pain. Assessing the risk factors and defining mechanisms in pain chronification will guide us to develop preventive measures and effective treatment methods.

Key words: sensitization; facilitation; disinhibition; reorganization; comorbidity

\section{A}

kut ağrı, kişide hoşa gitmeyen duyusal ve duygusal bir deneyim olmakla birlikte, gerçek ya da potansiyel doku hasarı ile ilişkili, yaşamsal ve erken bir uyarı belirtisidir. Akut ağrılar, travma, operasyon, yanık, inflamasyon gibi nedenlerle gelişebilir. Hayatımız boyunca, bir şekilde akut ağrı ile karşılaşırız. Boyun ağrısı genel popülasyonda \%30-50 sıklıkta gözlenir. ${ }^{[1]}$ Bel ağrısının hayat boyu prevalansı ise \%84'ler düzeyine ulaşmaktadır. ${ }^{[2]}$ Akut bel ağrısı için genellikle süre altı haftadan kısa olarak tanımlanırken, kronik bel ağrısı 12 haftadan uzun süren ağrı için kullanılmaktadır. Kronik bel ağrısı, yaş gruplarına ve cinsiyete göre prevalansı değişmekle birlikte, genellikle akut bel ağrısı olan bireylerin \%5-10'unda kronikleşebileceği bildirilmektedir. ${ }^{[3]}$ Kronik ağrı, kişi ve etkileşimde bulunduğu çevresinde hayat kalitesini bozan, ıstırap veren, iş-güç ve verimlilik kaybına neden olan önemli bir sağlık problemidir. Hastane başvurularında kronik bel ağrısı ön sıralarda yer almaktadır. Akut ağrının tanı ve tedavisi daha kolaydır. Ancak, akut ağrı erken tanı konulup, risk faktörleri belirlenip, etkin tedavi edilmez ise, kronik ağrıya dönüşebilir. Çevresel, genetik, psikososyal ve nörofizyolojik faktörler kronik ağrı semptomatolojisinde önemli belirleyiciler arasındadır. Kronik bölgesel kas-iskelet sistemi ağrıları, zamanla kronik yaygın ağrıya da dönüşebilmektedir. ${ }^{[4]}$ Ağrının kronikleşmesine neden olan faktörler ve mekanizmaların bilinmesi, hem önleyici yaklaşımların oluşturulmasına hem de etkin tedavi yöntemlerinin uygulanabilmesine ışık tutacaktır.

\section{PATOFIZYOLOJIK MEKANIZMALAR}

Ağrı duyusu bireysel farklılıklar gösterir. Ağrı nöroanatomisi ve nörofizyolojisi hakkındaki bilgilerimizi kısaca hatırlamak, akut ve kronik ağrıda yer alan nosiseptif/inflamatuvar ve nöropatik ağrı mekanizmalarını anlamamızı kolaylaştıracaktır.

Nosiseptörler, deri, kas, eklem gibi subkutan dokulardaki ağrı reseptörleridir. Termal, mekanik, kimyasal nitelikteki ağrılı uyarılar, membrandaki reseptörleri (transient receptor potential-TRP) depolarize eder. Bu uyarı, A-delta ve $C$ lifleri ile spinal kord arka köküne

- İletişim adresi: Prof. Dr. Işın Ünal-Çevik, Hacettepe Üniversitesi Tıp Fakültesi, Nöroloji Anabilim Dalı, Ağrı Ünitesi, Ankara Tel: 0312 - 3052585 e-posta: isin.unalcevik@gmail.com

- Geliş tarihi: 20 Șubat 2017 Kabul tarihi: 20 Șubat 2017 
iletilir. Nosiseptif duyusal nöronlar glutamat, nöropeptidler (substance $\mathrm{P}, \mathrm{CGRP}$ ), somatostatin ve galanin (nörotransmitter) ile arka boynuzdaki nöronları uyarir. ${ }^{[5]}$ Nosiseptif bilgi, daha sonra spinal korddan talamusa iletilir. Talamus bazı nosiseptif uyarıları serebral kortekse taşır. Fonksiyonel manyetik rezonans (MR) görüntülerde BOLD (blood oxygen level dependant) sinyal artışı olan bölgeler, ağıı fizyolojisi ile ilişkilendirilir. Uygulanan uyarıya (sıcak, soğuk, basınç, elektrik şoku, iskemi vb.) bağlı olarak farklı bölgeler ön plana çıkmakla birlikte, primer ve sekonder somatosensöriyel korteks, insular korteks, anterior ve orta singulat korteks, posterior singulat girus ve talamus ağrı ile ilişkili merkezler olarak değerlendirilebilir. ${ }^{[6]}$ Somatosensöriyel korteks nöronları, ağrının lokalizasyon ve şiddetinden sorumludur ve ağrı algısı için küçük bir bölgeye sahiptir. Kortekste, özellikle singulat ve insular korteks, ağrı algısında aktif bölgelerdir. Bu bölgeler, nosiseptif uyarı ile güçlü bir şekilde aktive olur; ağrının affektif ve motivasyonel boyutundan sorumludur. ${ }^{[7]}$

Kronik ağrılı hastalarda nöropatik ağrı komponentinin varlığı azımsanmayacak kadar fazladır. ${ }^{[8]}$ Kronik inflamasyon veya doku hasarı gibi durumlarda nosiseptörlerin eşik değerleri değişebilir. Sensitizasyon (duyarlı hale gelme), bir nosiseptif nöronun normal bir girdiye karşı artmış cevaplılığı ve/veya eşik altındaki bir uyarıya yanıt oluşturmasıdır. ${ }^{[9]}$ Sensitizasyon kavramı, hem ağrı eşik değerinin düştüğünü hem de eşik değer üstünde oluşturulan yanıtın olması gerektiğinden fazla olduğunu anlatmaktadır. Sensitizasyon, periferik veya santral kökenli olabilir. Uluslararası Ağrı Çalışma Birliği (IASP), periferik sensitizasyon kavramını, periferdeki nöronların uyarıya artmış yanıtlılığı veya bu nöronlarda ağrı oluşturan eşik değerin düşmesi; santral sensitizasyon kavramını ise, santral sinir sistemindeki nosiseptif nöronların normal veya eşik değerin altındaki afferent uyarılara karşı artmış yanıtıılığı şeklinde tanımlamıştır. ${ }^{[10]}$ Hiperaljezi, allodini gibi klinik bulgular, sensitizasyon varlığına işaret eder. ${ }^{[11]}$

Hasarlı hücrelerden salınan pek çok kimyasal (bradikinin, substance $\mathrm{P}$, nerve growth factor [NGF-sinir büyüme faktörü], ATP, histamin, serotonin, prostaglandinler, lökotrienler, asetilkolin vb.) sensitizasyonu tetikleyebilir. Bu maddeler/moleküller, kalıcı bir hasar sonrasında $C$ liflerini tekrarlayıcı bir şekilde ateşler ve dorsal boynuz nöron yanıtı progresif olarak artar. ${ }^{[12]}$ Tekrarlayıcı ağrılı uyaranlar, dorsal boynuz nöronlarında uzun-süreli değişiklikler yapar. ${ }^{[13]}$ Bu değişiklikler, santral sinir sisteminde NMDA aracılı uzun süreçli güçlenme (long-term potentiation -LTP) sonrası oluşan değişikliklere benzer ve dorsal boynuz nöronlarında ağrı hafizası oluşumuna temel teşkil eder. ${ }^{[14]}$ Kronik ağıı durumlarında, fosforilasyon gibi enzimatik değişiklikler ve sonrasında efektör proteinleri etkileyen c-fos gibi transkripsiyon faktörlerinin aktivitesinin değişmesiyle de iyon kanallarının aktivasyon eşik değerleri değişebilir. ${ }^{[15]}$ Dorsal boynuz nöronlarında fonksiyonel ve latent sinaptik bağlantılar vardır. Latent bağlantılar, güçlü nosiseptif uyarılarda fonksiyonel hale gelir, nöronal re-organizasyon ile yeni reseptif alanların oluşmasına neden olur. Kronik ağrı durumlarında, periferik sinirlerden peptid ve glutamat salınımı spinal kordda nörokinin ve NMDA reseptörlerinin aktive olmasına neden olur. Devamlı bir uyarı durumunda, bu reseptörler daha kolay uyarılabilir hale gelir ve nöron yanıtı artar; bu durum - "wind up"- "temporal sumasyon" olarak adlandırılır. ${ }^{[13]}$

Normal durumlarda, santral sinir sisteminden spinal korda ağrı algısını azaltıcı sinyaller mevcuttur. Prefrontal korteks, periakuaduktal gri cevher ve rostral ventral medulladaki aktivasyon, endojen ağrı inhibisyonundan sorumludur. ${ }^{[16]}$ Ancak, pek çok kronik ağrılı durumlarda, inen yollardaki disregülasyon, yani ağrıyı durdurucu (antinosiseptif) mekanizmaların yeterli işlev görememesi ve ağrının fasilitasyonu[ ${ }^{[17]}$ gözlenmektedir. ${ }^{[18]} \mathrm{Bu}$ nedenle, kronik ağrılı hastalarda ağrılı uyaranlara artmış cevap - hipersensitivite (temporal sumasyon) ve eş zamanlı iki ağrılı uyarı verildiğinde ağrı inhibisyonunda (koşullu-ağrı modülasyonu) azalma gözlenir. ${ }^{[16]}$ Kronik ağrılı ${ }^{[19-23]}$ ve kronik bel ağrısı olan bireylerin beyin görüntüleme çalışmalarında yapısal değişiklikler de gözlenmiştir. ${ }^{[20-22]}$

\section{RISK FAKTÖRLERi}

Kronik kas-iskelet sistemi ağrı gelişiminde; yaş, cinsiyet, eğitim düzeyi, meslek, işsizlik, obezite, sigara, hareketsizlik (sedanter hayat), uzun süreli şiddetli ağrı, geçirilmiş cerrahiler, genetik, psikososyal ve çevresel risk faktörlerinin rol oynadığı düşünülmektedir. [24] ileri yaş, kronik kas-iskelet sistemi ağrıları için bir risk oluştururken ${ }^{[25]}$, hayatın çok erken dönemelerinde maruz kalınan stresler ve ağrılı durumlar da bireyde ağrı duyarlılığına risk oluşturabilmektedir. ${ }^{[26,27]}$ Bazı bireyler genetik olarak da kronik ağrıya daha yatkındır. ${ }^{[28]}$ Genetik mutasyonlar, reseptörlerin veya nörotransmitter sentez ve salınımı ile ilişkili yapıların fonksiyonunu değiştirerek ağrıya yatkınlık yaratabilmektedir. Hatta, ağrı kesicilere cevaplılık dahi genetik farklılıklardan kaynaklanmaktadır. Bu bireylerde, $\beta$-adrenerjik reseptör, delta-opiod reseptör, GABA reseptör polimorfizmi, COMT polimorfizmleri, Nav1,7 gen mutasyonları, CNS potasyum kanal geni (KCNS) mutasyonları ve CGRP duyarlılığı tanımlanmaktadır. Ağrının kronikleşmesinde epigenetik faktörler de önemlidir. ${ }^{[29]}$ 
Kronik bölgesel kas-iskelet sistemi ağrıları, sıkıkla kronik bel, boyun ağrıları, alt ya da üst segment ağrıları, sağ ya da sol taraflı ağrılar olarak tanımlanmaktadır. ${ }^{[4]}$ Bazı bireylerde, kronik bölgesel kas-iskelet sistemi ağrısı zamanla kronik yaygın ağrıya dönüşür. Kronik yaygın ağrı prevalansı \%11-15 arasında bildirilmektedir. Bu kişilerde, hem ağrının şiddeti artış göstermekte hem de ağrılı bölge daha yaygın hale gelmektedir. Kronik yaygın ağrısı olan bireylerde, santral sinir sisteminde modifikasyonlar da gelişir. Risk faktörleri arasında; kadın cinsiyeti, ileri yaş, ailede ağrı öyküsünün varlığı, depresif duygu durumu ve bazaldeki ağrı bölgeleri sayılmaktadır. ${ }^{[4]}$

Psikiyatrik durumlar içinde, kronik ağrı sendromları ile depresyon \%5-22 oranında birliktelik göstermektedir. ${ }^{[30]}$ Yapılan çalışmalarda, ağrının depresyonu indükleyebilmesi yanında depresyonu olan bireylerde kronik ağrı sendromların görülme olasılığının da daha fazla olduğu gösterilmiştir. Benzer şekilde, anksiyete bozuklukları ve santral sensitizasyon ilişkili sendromlar arasında çift yönlü bir ilişki mevcuttur. ${ }^{[30]}$ Katastrofiye yatkın (bir olayı olduğundan daha da kötü olduğunu düşünen) bireylerde kronik bel ağrısı gelişimi daha sık gözlenmiştir. ${ }^{[31]}$ Uyku-uyanıklık döngüsündeki değişiklikler de kronik ağıı yatkınlığı açısından önemlidir. ${ }^{[32]}$ Boyun ağrısı gelişimini takiben, hastaların \%53,7'sinde insomni bildirilmiştir. ${ }^{[33]}$ Derin uykuda alfa aktivitesindeki artış, uykunun dinlendirici ve yenileyici niteliğini bozar. Uyku kalitesindeki bozukluk yorgunluk ve ağrı ile ilişkilendirilmektedir. Uyku döngüsü ile de bağlantılı olarak, nöroendokrin sistemdeki değişiklikler santral sensitizasyon risk faktörleri arasında sayılmaktadır. Santral sensitizasyonlu bireylerde, hipotalamus-hipofiz-adrenal aks disfonksiyonu, kortizol eksikliği, ACTH seviyelerinde farklılıklar, büyüme hormon değişiklikleri izlenmiştir. Otonom sinir sisteminde parasempatik sistem aktivitesinin azalması, sempatik sistemin aşırı aktivitesi ile strese verilen yanıtın değişmesi, sensitizasyonu indükleyebilmektedir. ${ }^{[34]}$

\section{PATOFIZYOLOJi TEMELLi TEDAVILER}

Ağrıda nosiseptif ve inflamatuvar ağrı mekanizmaları hakim ise basit analjezikler (parasetamol), nonsteroidal ağrı kesiciler ya da daha şiddetli ağrılarda güçlü analjezikler olarak opioidler kullanılmaktadır. Kronik ağrı, tedavisi güç bir hastalıktır. Tedavideki ana hedef, hastanın ağrısını azaltarak tekrar fonksiyon kazanmasını sağlamaktır. Kronik ağrılı hastaların, ağrı uzmanlarına yönlendirilmeden önce, kullanabilecekleri pratik bir tanı ve tedavi yaklaşım kılavuzu da vardır. ${ }^{[35]}$ Kronik ağrılı hastalarda komorbid durumlar ve risk faktörleri ayrıntılı olarak analiz edilip, bunlara yönelik tedavi modaliteleri uygulanmalıdır.
Optimal tedavi, çok titiz bir değerlendirme sonrası ve multimodal, multidisipliner bir yaklaşım (farmakoterapi $^{[36,37]}$, fizik tedavi[ ${ }^{[38]}$, bilişsel-davranışçı tedavi[ ${ }^{[39]}$ ve girişimsel tedavi[ ${ }^{[40]}$ ) ile sağlanabilir. Kronik bel ve boyun ağrıları karma tipte ağrılardır. Yani bunlarda hem nosiseptif/inflamatuvar hem de nöropatik ağrı ve santral sensitizasyon mekanizmaları rol oynar. ${ }^{[41]}$ Kronik ağrıda yer alan nöropatik ağrı/santral sensitizasyon komponentler nedeniyle, medikal tedavi yaklaşımında bu mekanizmalar da hedeflenmelidir. ${ }^{[41]}$ Farmakoterapide adjuvan analjezikler (antidepresanlar, antikonvülsanlar, topikal ajanlar vb.) yanında, seçilmiş olgularda uygulanan invaziv girişimsel tedavilerin (faset eklem blokları, epidüral steroid enjeksiyonları, selektif sinir blokları, sakroiliak eklem enjeksiyonları, intratekal infüzyonlar ve spinal kord stimülasyonu) yeri de önemlidir.

\section{KAYNAKLAR}

1. Shahidi B, Curran-Everett D, Maluf KS. Psychosocial, Physical, and Neurophysiological Risk Factors for Chronic Neck Pain: A Prospective Inception Cohort Study. J Pain 2015;16(12):1288-99. Crossref

2. Violante FS, Mattioli S, Bonfiglioli R. Low-back pain. Handb Clin Neurol 2015;131:397-410. Crossref

3. Parthan A, Evans CJ, Le K. Chronic low back pain: epidemiology, economic burden and patient-reported outcomes in the USA. Expert Rev Pharmacoecon Outcomes Res 2006;6(3):359-69. Crossref

4. Larsson B, Bjork J, Borsbo B, Gerdle B. A systematic review of risk factors associated with transitioning from regional musculoskeletal pain to chronic widespread pain. Eur J Pain 2012;16(8):1084-93.

5. Costigan $M$, Woolf, CJ. Pain: molecular mechanisms. J Pain 2000;1(3 Suppl):35-44.

6. Peyron R, Laurent B, Garcia-Larrea L. Functional imaging of brain responses to pain. A review and meta-analysis (2000). Neurophysiol Clin 2000;30(5):263-88.

7. Derbyshire SW, Jones AK, Gyulai F, Clark S, Townsend D, Firestone LL. Pain processing during three levels of noxious stimulation produces differential patterns of central activity. Pain 1997;73(3):431-45.

8. Timmerman $\mathrm{H}$, Wilder-Smith $\mathrm{O}$, van Weel $\mathrm{C}$, Wolff $\mathrm{A}$, Vissers $K$. Detecting the neuropathic pain component in the clinical setting: a study protocol for validation of screening instruments for the presence of a neuropathic pain component. BMC Neurol 2014;14:94. Crossref

9. Gold MS, Gebhart GF. Nociceptor sensitization in pain pathogenesis. Nat Med 2010;16:1248-57. Crossref

10. Turk DC, Rudy TE. IASP taxonomy of chronic pain syndromes: preliminary assessment of reliability. Pain 1987;30(2):177-89.

11. Woolf CJ. What to call the amplification of nociceptive signals in the central nervous system that contribute to widespread pain? Pain 2014;155(10):1911-2. Crossref

12. Scholz J, Woolf CJ. Can we conquer pain? Nat Neurosci 2002;5 Suppl:1062-7.

13. Baron R, Hans G, Dickenson AH. Peripheral input and its importance for central sensitization. Ann Neurol 2013;74(5):630-6. Crossref 
14. Price TJ, Inyang KE. Commonalities between pain and memory mechanisms and their meaning for understanding chronic pain. Prog Mol Biol Transl Sci 2015;131:409-34. Crossref

15. Woolf $\mathrm{CJ}$. Central sensitization: uncovering the relation between pain and plasticity. Anesthesiology 2007;106(4):8647. Crossref

16. Staud R. Abnormal endogenous pain modulation is a shared characteristic of many chronic pain conditions. Expert Rev Neurother 2012;12(5):577-85. Crossref

17. Porreca F, Ossipov MH, Gebhart GF. Chronic pain and medullary descending facilitation. Trends Neurosci 2002;25(6):319-25.

18. Ossipov $\mathrm{MH}$, Morimura K, Porreca F. Descending pain modulation and chronification of pain. Curr Opin Support Palliat Care 2014;8(2):143-51. Crossref

19. Apkarian AV. Human Brain Imaging Studies of Chronic Pain: Translational Opportunities. In: Kruger L, Light AR, editors. Translational Pain Research: From Mouse to Man. Boca Raton, FL: CRC Press/Taylor \& Francis; 2010. Chapter 15.

20. Lloyd DM, Helbig T, Findlay G, Roberts N, Nurmikko T. Brain Areas Involved in Anticipation of Clinically Relevant Pain in Low Back Pain Populations With High Levels of Pain Behavior. J Pain 2016;17(5):577-87. Crossref

21. Mao C, Wei L, Zhang Q, Liao X, Yang X, Zhang M. Differences in brain structure in patients with distinct sites of chronic pain: A voxel-based morphometric analysis. Neural Regen Res 2013;8(32):2981-90. Crossref

22. Mao CP, Yang HJ. Smaller Amygdala Volumes in Patients With Chronic Low Back Pain Compared With Healthy Control Individuals. J Pain 2015;16(12):1366-76. Crossref

23. Ruscheweyh R, Deppe $M$, Lohmann $H$, Stehling C, Flöel A, Ringelstein EB, Knecht $S$. Pain is associated with regional grey matter reduction in the general population. Pain 2011;152(4):904-11. Crossref

24. Manchikanti L, Singh V, Falco FJ, Benyamin RM, Hirsch JA. Epidemiology of low back pain in adults. Neuromodulation 2014;17 Suppl 2:3-10. Crossref

25. van Hecke $\mathrm{O}$, Torrance $\mathrm{N}$, Smith $\mathrm{BH}$. Chronic pain epidemiology and its clinical relevance. $\mathrm{Br} J$ Anaesth 2013;111(1):13-8. Crossref

26. Kajantie E. Fetal origins of stress-related adult disease. Ann N Y Acad Sci 2006;1083:11-27.

27. Nishinaka T, Nakamoto K, Tokuyama S. Influence of early life stress on the chronic pain in maturation period. Nihon Yakurigaku Zasshi 2016;148(3):134-8. Crossref

28. Zorina-Lichtenwalter $\mathrm{K}$, Meloto CB, Khoury S, Diatchenko L. Genetic predictors of human chronic pain conditions. Neuroscience 2016;338:36-62. Crossref

29. Bai G, Ren K, Dubner R. Epigenetic regulation of persistent pain. Transl Res 2015;165(1):177-99. Crossref
30. AdamsLM,TurkDC. Psychosocial factors and central sensitivity syndromes. Curr Rheumatol Rev 2015;11(2):96-108.

31. Wertli MM, Eugster R, Held U, Steurer J, Kofmehl R, Weiser S. Catastrophizing -a prognostic factor for outcome in patients with low back pain: a systematic review. Spine J 2014;14(11):2639-57. Crossref

32. Menefee LA, Cohen MJ, Anderson WR, Doghramji K, Frank $E D$, Lee $H$. Sleep disturbance and nonmalignant chronic pain: a comprehensive review of the literature. Pain Med 2000;1(2):156-72.

33. Kim SH, Lee DH, Yoon KB, An JR, Yoon DM. Factors Associated with Increased Risk for Clinical Insomnia in Patients with Chronic Neck Pain. Pain Physician 2015;18(6):593-8.

34. Generaal E, Vogelzangs N, Macfarlane GJ, Geenen R, Smit JH, Penninx BW, Dekker J. Reduced hypothalamic-pituitaryadrenal axis activity in chronic multi-site musculoskeletal pain: partly masked by depressive and anxiety disorders. BMC Musculoskelet Disord 2014;15:227. Crossref

35. Smith BH, Hardman JD, Stein A, Colvin L; SIGN Chronic Pain Guideline Development Group. Managing chronic pain in the non-specialist setting: a new SIGN guideline. $\mathrm{Br} J$ Gen Pract 2014;64(624):e462-4. Crossref

36. Beal BR, Wallace MS. An Overview of Pharmacologic Management of Chronic Pain. Med Clin North Am 2016;100(1):65-79. Crossref

37. Haas M, De Abreu Lourenco R. Pharmacological management of chronic lower back pain: a review of cost effectiveness. Pharmacoeconomics 2015;33(6):561-9. Crossref

38. Geneen LJ, Moore RA, Clarke C, Martin D, Colvin LA, Smith $\mathrm{BH}$. Physical activity and exercise for chronic pain in adults: an overview of Cochrane Reviews. Cochrane Database Syst Rev 2017;1:CD011279. Crossref

39. Monticone M, Ambrosini E, Cedraschi C, Rocca B, Fiorentini R, Restelli M, Gianola S, Ferrante S, Zanoli G, Moja L. Cognitive-behavioral Treatment for Subacute and Chronic Neck Pain: A Cochrane Review. Spine (Phila Pa 1976) 2015;40(19):1495-504. Crossref

40. Manchikanti L, Abdi S, Atluri S, Benyamin RM, Boswell MV, Buenaventura RM, Bryce DA, Burks PA, Caraway DL, Calodney AK, Cash KA, Christo PJ, Cohen SP, Colson J, Conn A, Cordner H, Coubarous S, Datta S, Deer TR, Diwan S, Falco FJ, Fellows B, Geffert S, Grider JS, Gupta S, Hameed H, Hameed M, Hansen H, Helm S 2nd, Janata JW, Justiz R, Kaye $A D$, Lee M, Manchikanti KN, McManus CD, Onyewu O, Parr AT, Patel VB, Racz GB, Sehgal N, Sharma ML, Simopoulos TT, Singh V, Smith HS, Snook LT, Swicegood JR, Vallejo R, Ward SP, Wargo BW, Zhu J, Hirsch JA. An update of comprehensive evidence-based guidelines for interventional techniques in chronic spinal pain. Part II: guidance and recommendations. Pain Physician 2013;16(2 Suppl):S49-283.

41. Clauw DJ. Diagnosing and treating chronic musculoskeletal pain based on the underlying mechanism(s). Best Pract Res Clin Rheumatol 2015;29(1):6-19. Crossref 